\title{
A Personal View
}

\author{
Psychiatrists-An Endangered Species?* \\ John Harrington, Honorary Consultant Psychiatrist, Central Birmingham Health District, Selwyn Road, Edgbaston, \\ Birmingham B16 0SH
}

The Darwinian model is employed to study the phylogeny and taxonomy of psychiatrists in the UK. External hazards which could threaten psychiatric practice are examined and the part that psychiatrists themselves play in bringing abouttheir difficulties are emphasised. Ways of ensuring a more satisfactory and secure future for psychiatrists are explored.

A phylogenetic examination of psychiatrists would show that until 1948 they enjoyed a protected existence in large asylums presided over by all-powerful tribal chiefs called medical superintendents whose stipend depended on the number of inmates who were often compulsorily confined behind the walls of their domain. With the advent of the NHS things began to change. Psychiatrists who were lower down in the pecking order rebelled against the horde fathers who had become scapegoats for their discontents so superintendents were eliminated.

Intrepid psychiatrists began to emerge from the protective environment of their isolated institutions and face the dangers of the outside world and extend their activities in new directions, seizing the opportunity to expand into virgin forests like the neuroses.

Cautious psychiatrists sounded warning bells about the dangers of venturing into uncharted territories. Desmond Curran saw the floating of a company he called 'Psychiatry Unlimited' as a risky investment and warned psychiatrists against straying into fields that were not traditionally theirs. This was ignored by some who seized the opportunity to extend the power and influence of psychiatrists in the arts, literature and politics.

The call to pull down the traditional habitat of the psychiatrist was soon echoed in several enquiries whch followed scandals about the neglect and ill-treatment of patients which was by then feared to be endemic in large mental hospitals. After a short debate, it was agreed that traditional mental hospitals were like dinosaurs, had become too large and poorly adapted for new functions and should be quickly exterminated.

It was confidently predicted that the creation of small new units in District General Hospitals and the treatment of most psychiatric patients in the community would eliminate the need for further enquiries into widespread abuses that had been condoned, if not actually created, by psychiatrists.

* Based on a valedictory address given at the Birmingham Medical Institute on 5 January 1988.
Unfortunately many lessons about the containment of the insane in the community in the last century were overlooked.

Loss of habitat is claimed by biologists to be one of the main factors endangering a species. Have psychiatrists condoned the loss of their traditional habitat without proper consideration of the new? Transfer to the District General Hospital has not proved to be all that many hoped.

Their resources are pooled and threatened by new managers who control their territory, know little of psychiatry and bend to the shroud-waving of other specialists. Their physical space in hospital has been cut to the bone. They are persuaded that lush new pastures await them in the community, but when they venture into the community they do not often find themselves welcome by social service departments who have been given much of the legal responsibility for the care of psychiatric patients in the community. General practitioners then accuse them of encroaching on their territory without their permission; so many retreat into a much diminished hospital base.

Species are also distinguished by boundaries. There are ongoing territorial disputes between psychiatrists and other mental health professionals who are also competing for space and resources. The DHSS finds difficulty in knowing the rightful and proper place for psychologists, psychiatric nurses, social workers and other mental health professionals who want to push the psychiatrist out of his central position in the cuckoo's nest. The Government would like them to take over much of the psychiatrist's work if they could do it properly because they cost less.

It would appear to be official policy to remove whole categories of patient like neurotics from the ambit of psychiatrists, and psychologists have been welcomed by GPs to help fill the gap. Pressure groups see mentally handicapped patients as seldom requiring the attention of a psychiatrist.

The encroachment of other species who are hungry for the psychiatrists' territory still goes on and, if unchecked, loss of habitat could reach the stage of other threatened species who only survive as bygone curiosities in zoos. Psychiatrists accept they cannot survive as an isolated species but are concerned about enforced symbiotic relationships 
with other groups that threaten their clinical independence through structures like the multi-disciplinary team.

While an increasing number of patients are now regarded as outside the remit of psychiatrists, they are expected to take on others for whom they can do little and who often reject their attention. They are asked to accept responsibility for patients who refuse to take responsibility for themselves and who persistently disregard treatment plans or warnings about alcohol or drug consumption. Psychiatrists are reluctant to blame patients for self-inflicted conditions but object when they are blamed for therapeutic failures due to lack of co-operation.

The psychiatrist's freedom of action is increasingly restricted by a ball and chain called a job description. There was a time when psychiatrists were allowed a fair degree of latitude in deciding how best to carry out their professional duties and provide appropriate care for their patients. Current job descriptions lay down in considerable detail what the consultant must do and often this is far more than he can do properly. It matters little to his masters that there are inadequate resources to carry out all the tasks allotted.

Complaints that the work-load would be feasible only if sufficient support staff were available are ignored. There is little or no time for the development of special interests or new initiatives.

The latter-day psychiatrist is placed in a Catch 22 situation. If he is conscientious about his clinical commitments he will devote almost his whole time to patient care, ignoring his teaching, administrative and management functions or vice versa. Birley ${ }^{1}$ summed up this dilemma for psychiatrists by the harsh conclusion that, though psychiatry offers a fascinating and rewarding career, in future, it may be impossible to practise it properly because of lack of staff and resources. Perhaps his prediction has already come true and if so psychiatrists must ask themselves, if they are prevented from the proper practice of psychiatry, are they not already on the same path as the Dodo?

While Winston Churchill was suspicious of psychiatrists and their potential for harm, an archetypal opponent was a neurologist who suggested that the best thing to do with psychiatrists was to abolish them. The late Henry Miller ${ }^{2}$ in a 1969 paper entitled 'Psychiatry-Medicine or Magic?' told the World Psychiatric Association that a few years before he and a colleague had founded the society for the abolition of psychiatrists. Miller saw psychiatry as little more than neurology without physical signs, implying that psychiatry was at best a minor subspeciality of neurology.

Miller felt the most important task for the psychiatrist was to expose hidden organic causes for symptoms that had been missed by physicians. He regarded psychiatry as a much abused subject because of psychiatrists' reluctance to restrict their activities to the narrow field in which he felt they were genuinely qualified to operate. Miller thought that psychiatrists had duped the public because they did not admit the simple fact that a psychiatrist is no more than a physician who takes a proper history at the first consultation and sees fewer patients. He condemned psychic determinism, the concept of illness due to emotional causes and psychogenesis as a game for amateurs. Unfortunately Miller's crude and superficial judgements have survived and gave strength to the crusade against psychiatrists launched by well-publicised proclamations of Laing and Szasz. Though these and other critics were never taken very seriously by psychiatrists, they caught the public's imagination and their views persist.

Professor Rosenhan, ${ }^{3}$ a psychologist, showed that supposedly competent American psychiatrists failed to recognise fake schizophrenics who were admitted for psychiatric assessment. He rubbed salt in the wound by disclosing that the only people to recognise them as phoney were genuine schizophrenics in the same ward. Prominent scientists like Koestler remarked on the striking discrepancies in diagnostic classification and treatment of psychiatric patients in the UK and United States. Blow after blow was struck against the psychiatrist's professional pride and the attacks have continued unabated.

Psychiatrists have been accused of converting essentially social problems into illnesses to extend their empire; of labelling those who are dragged down by impossible social circumstances as mentally ill and treating them with drugs and ECT when their problems could be more cheaply and effectively dealt with by others. They are then censured for regarding mental disorders as no different from physical illnesses by ignoring social and political dimensions. There are allegations of ignoring moral and ethical issues, of slighting the views of other mental health professionals and making important decisions without due consideration of alternative approaches. The psychiatrist is then chided for being arrogant, paternalistic, and for compulsorily detaining thousands of patients each year without proper concern for their human rights. Psychiatrists have been defamed by the slanderous suggestions that having created the concept of mental illness they have developed and used it largely out of self interest. If such a list of indictments were true psychiatrists would deserve extinction.

Only by persistent efforts of their College have British psychiatrists succeeded in disassociating themselves from psychiatrists in the USSR who are seen as little more than agents of the state by enforcing treatment on political deviants in ways prescribed by their masters.

Rawnsley addressed the sorry plight of British psychiatrists when he spoke of psychiatry in jeopardy. Kendell $^{5}$ said our academic research record compares unfavourably with other branches of medicine and the heyday of British psychiatric research is probably past and the future outlook in Britain is bleak.

Other hospital specialists find it easy to make psychiatrists feel they are members of a low-prestige specialty who, having failed to make it in more competitive branches of medicine or surgery, must be regarded as largely outside the mainstream of medical practice. Psychiatrists are still expected to carry out an in-depth psychiatric evaluation in a few minutes in an open ward where the only privacy is a curtain drawn round the patient's bed. They are asked to express an immediate opinion when it cannot be done properly and often do so without protest. 
The psychiatrist is seen as a convenient dumping ground for his colleagues' failures. Late referral makes a difficult problem impossible, and appropriate patients for whom he could do something are not referred. The patient sometimes gets the impression that referral to the psychiatrist is a form of punishment for not getting better. Another trick is not to tell the patient he is being referred to a psychiatrist so that when he finds out rapport is ruined.

The psychiatrist is made to feel small when unsuspected organic disease is discovered in a patient he has been treating but is not given the opportunity to reciprocate when an obviously depressed patient has been subjected to years of fruitless investigations by other specialists.

Public prejudice against mental illness comes largely from ignorance and fear so displacement on to the psychiatric profession is inevitable. The public regard psychiatrists with apprehension and suspicion which they rationalise by calling them trick cyclists or shrinks. They enjoy newspaper cartoons which portray psychiatrists as idiotic figures of fun. They yearn for an omnipotent saviour and are upset when the psychiatrist is unable to fulfil unrealistic expectations like the instant relief of anxiety in an uncertain world.

Such unfavourable views of psychiatrists would improve if the public's generally positive attitude to the medical profession included psychiatrists, but they are often not held to be 'proper' doctors despite their medical training.

Lawyers are ambivalent about psychiatrists because of the power they wield in deciding whether a patient is to be excused for his actions on grounds of mental illness. Politicians have decided that mental health is too important to be left in the hands of psychiatrists, they are not to be trusted and their clinical activities need to be controlled by statute, so in 1983 mandatory second opinions were imposed on consultants before they could proceed with the treatment of detained patients.

The Mental Health Act Commission has shown itself to be overtly anti psychiatrist. The first draft code of practice, now thankfully modified, suggested it was necessary to put them in a procedural straitjacket by laying down a code of conduct which was alien to well-established clinical practice. Likewise the DHSS through its Health Advisory Service is keen to put psychiatrists in bondage by proselytising a uniform approach to treatment that lacks an adequately researched basis and discourages innovative ideas which might lead to progress.

Psychiatrists have found themselves in a double bind. There are considerable pressures on them to fit into the social and economic ethos of the times and allow themselves to be swayed by political considerations and to ignore what they see as the real interests of patients. As Hill $^{6}$ pointed out, if they allow their views about what is right to be influenced by ideologies which are expedient at the time, they may sacrifice the integrity and objectivity which are essential to their survival as a professional group.

Kathleen Jones ${ }^{7}$ showed scant regard for the psychiatrists' medical qualifications when she accused them of sounding the retreat, of opting out of the real frontiers of psychiatry and hiding behind the medical model and behaving like doctors whose only interest is in biological psychiatry, biochemical explanations of mental disorders and physical methods of treatment.

She is right when she says that the power structure behind psychiatrists is that of the medical profession so it is hardly surprising that they veer towards biological psychiatry whenever they feel threatened. She is wrong when she accuses them of professional restrictiveness and unwillingness to engage in new initiatives in partnership with other disciplines. Many of the restrictions have been imposed upon them and collaborative efforts are generally discouraged or inadequately funded.

While psychiatrists are ready to acknowledge dangers from without, they appear unwilling to accept there are dangers from within. They appear to welcome the chance to argue against themselves in the media and to indulge in public displays of self flagellation which damages their image.

Psychiatrists are fortunate in having an extensive therapeutic menu to choose from but there are those who would willingly restrict the diet on which psychiatrists live. Greben $^{8}$ pointed out that an increasing number of psychiatrists seem willing to eliminate psychotherapy as an integral part of psychiatry and to delegate its practice to others. Then there are those who seem equally willing to do without physical methods of treatment. Psychiatrists should remind themselves of the dangers of restricting their therapeutic menu and remind themselves of the giant panda which is endangered because it only eats a certain type of bamboo shoot.

The survival potential of a species depends on its structural and functional organisation. Homogeneous species are less troubled by in-fighting but where a genus is split into distinct subspecies, territorial and boundary conflicts arise. A taxonomic examination shows psychiatrists are now divided into a number of subspecies each, with their own territories and jealously guarded characteristics like child, forensic, subnormality, psychogeriatric psychiatrists etc.

While such subspecies have expanded into new territories, psychiatrists as a whole have paid a heavy price by becoming a multivariate species. The parent stock from which all the others have been derived, the general psychiatrist, is now in danger of extinction. His territory has been invaded by subspecies and the pastures on which he used to graze are becoming overgrazed by others who have ousted him from a previously dominant position. The gradual demise of the general psychiatrist threatens unity of the species, making it more vulnerable to attack from predators. Rivalry between subgroups of psychiatrists has led to unproductive in-fighting so that energies that might have been devoted to warding off external threats have been dissipated. Behavioural and dynamic psychotherapies have tried to deny each other the right to exist. More serious has been the threat of some mutations to renounce their psychiatric heritage; some child psychiatrists want to break away and join the paediatricians.

People sometimes express surprise that psychiatrists so 
often seem unable to get on well with each other; after all they are supposed to be experts in interpersonal relationships and psychological understanding so how is it they so often seem unable to live in harmony? By way of rationalising their disagreements, psychiatrists try to present themselves as flexible eclectics able to prescribe a broad range of treatment with drugs or other physical methods; various forms of psychotherapy, either individually or in groups, etc; each prescribed according to patient needs. Unhappily the truth seems rather different. Research findings show how split they are, even within their subspecies.

Kreitman' ${ }^{9}$ showed how sharply they are categorised into 'organic' and 'psychological' groups. The organic group use the medical model and predominantly physical methods of treatment. The other group is interested in psychological factors, unconscious motives and interpersonal relationships. Later research by Cain \& Smail ${ }^{10}$ and then Pallis \& Stoffelmayr ${ }^{11}$ showed their professional approach has less to do with training and more to do with social attitudes and personality, so that the organic psychiatrist is likely to score highly on conservatism and tough mindedness while the psychiatrist favouring psychotherapy is more likely to be tender minded and radical. It seems that disagreements between psychiatrists may not be based on science or logic but on deeper reasons.

An important principle of evolutionary theory is the survival of the fittest. In the case of psychiatrists this may be seen as survival based on the ability to carry out the specialised functions required of psychiatrists. What makes a person fit to practise psychiatry? Obviously a psychiatrist must be adequately trained to carry out the professional tasks he has to perform. The College has made enormous efforts to ensure that today's career psychiatrist is trained to high academic standards but academic excellence does not guarantee the ability to apply knowledge effectively.

There is another ingredient of fitness, perhaps equal in importance, namely the personality of the psychiatrist. In some branches of medicine like pathology the personality of the doctor matters little to the patient though it may affect his colleagues. In psychiatric practice it is an entirely different matter, for the psychiatrist's personality may constitute a considerable hazard to the patient and affect the outcome of treatment. Not all psychiatrists acknowledge the problems arising from transference and countertransference, neglect of which can damage both parties. Hill ${ }^{6}$ felt that the risk to patients arising from the psychiatrist's own personality can be traced to inadequate or biased training. While proper training will reduce some of the hazards to patients, some personality traits appear to be unresponsive to training or a personal analysis and make a person unsuited to clinical psychiatry. The profession should pay much more attention to the selection of psychiatrists on the basis of temperamental suitability.

The conservation of a species depends on the possession of special features which distinguish it from other species and by which members can readily recognise each other as kin. Once characteristic features are lost a species loses its identity and is absorbed by another species or perishes.
Much has been said on the identity crisis affecting psychiatrists. Professor Querido saw psychiatrists as having an ill-defined identity and as merely part of a larger metaprofession in which people from different backgrounds like psychiatry, psychology, sociology join to form a composite group. Professor Kubie and others have argued in favour of the disappearance of the traditional psychiatrist and his replacement by a kind of hybrid composed of the genes of all the existing mental health professionals and for whom medical training would play only a very minor role.

If preservation of the psychiatrist's identity is important for their survival it would help if they could agree upon a group ego ideal. Do they want to be principally medical practitioners with a special interest in mental illness or a lot of other things besides? If they try to wear too many hats their image may be incongruous.

However psychiatrists see themselves they must accept that their self perspective is less important than how others see them. The work they do is conditioned not only by their own self image but the perceptions of others. Kathleen Jones said psychiatric practice is shaped, defined, and depends on society for its status. She added that psychiatrists are known as 20th century witch doctors: wise, powerful and capable of great good and great harm.

Psychiatrists are constantly reminded they have important functions as managers but many are uncertain about their administrative and management functions. They have been awarded the legal title of responsible medical officer but are uncertain of their real responsibilities because they are largely powerless to remedy deficiencies that lead to repeated crises and are blamed when things beyond their control affect their patients.

Health authorities are evasive when challenged on the psychiatrist's powers and responsibilities and important issues like their leadership role in the multidisciplinary team. Perhaps they are just a key worker like everybody else but have a special role as team scapegoat.

The survival of a species may be threatened if their activities are particularly hazardous. Psychiatrists are from time to time assaulted by their patients but serious injuries and deaths are rare though sadly death at their own hand is not uncommon. Do psychiatrists suffer high morbidity from stress disorders? Burnout is now a fashionable stress disorder among doctors in general and psychiatrists in particular.

Richard Mayou ${ }^{12}$ reviewed the Burnout Syndrome seeing it as having several related components; emotional exhaustion including tiredness, irritability, depression, excessive alcohol consumption, low productivity, feelings of low achievement and depersonalisation in the form of treating people as if they were objects. Some might say this is a not inaccurate description of some middle-aged psychiatrists who were once enthusiastic and dedicated practitioners. Are they suffering from burnout, a mid-career crisis, or what Merton and Stoffner call retreatism? Kathleen Jones suggests that retreatism may occur as a reaction to all the changes that have occurred through the repeated reorganisations of the health services. 
Psychiatrists are sometimes accused of whingeing about nothing and complaining that the work they do is not properly appreciated. Are professional satisfaction and contentment important? Morale is important but perhaps their survival depends more on their discontent provided it motivates them to fight to better the lot of their patients. Complacency, passivity and acceptance of the status quo are much greater threats.

Sickness is an important factor in the survival of any species. Medical practitioners as a whole suffer from unacceptably high levels of psychiatric illness, mainly depression and suicide, alcohol abuse and drug dependency. The evidence suggest psychiatrists are not notably sicker than other doctors.

Ensuring a future

Although psychiatrists face many threats there are few reasons to regard them as a seriously endangered species. Mental illness is not going to disappear and as long as they continue to provide skilled professional help in resolving the miseries brought about by mental illness they will survive. They must get their priorities right. The patient must always come first and never be regarded as an infernal nuisance who gets in the way of other obligations, however important these may seem. They cannot escape the reality of limited resources but should never willingly accept second best for their patients. It is no good moaning about their difficulties to politicians, for this only angers them, but they must be honest about what they can and cannot do within their resource allocation. They should disassociate themselves from policies that are clearly to the disadvantage of their patients. They must hold their corner against the other branches of medicine, regard themselves as proper doctors of equal rank and be prepared to assert themselves and compete with their professions. They must adapt their practices to unwelcome changes. If they merely try to maintain the status quo they will regress. Their future depends much on how others judge how well they do what they are expected to do; on whether what they are doing is judged to be worthwhile and effective and if their use of resources is better than the alternatives others might offer.

Their prime task is to be good psychiatrists. Hill ${ }^{6}$ addressed this question when he spoke of the qualities of a good psychiatrist. He saw the survival of psychiatry as a specialty needed by society as dependent on whether there are enough well trained psychiatrists who want to care for their patients.

He emphasised the dangers of consultants opting out of their clinical duties and pointed to the many temptations and avenues open to the psychiatrist who wishes to avoid his clinical responsibilities. Hill was right about the importance of well-trained clinicians dedicated to patient care, but if the psychiatrist of today opted out of the NHS bureaucracy and confined his activities to treating patients he would soon be taken over and disappear.

Academic status is closely linked with ongoing research, and ignorance about the basic mechanisms of mental illness make it particularly important for the psychiatrist to preserve a balance between the relief of suffering and the advance of knowledge. Murray ${ }^{13}$ said that it is no longer sensible to wait in the hope of a more adequate level of government funding for psychiatric research; other sources must be found. While formidable manpower issues darken the future for psychiatrists, potential recruits should not be deterred by inflexible training requirements that make it difficult for young psychiatrists to plan their own careers or change direction in their formative years.

Like others who are mostly financed out of the public purse, psychiatrists must expect to be accountable for what they do and accept the need for checks and controls on the quality and quantity of their work. Rawnsley emphasised the importance of keeping professional audit in their own hands. Peer group reviews must be seen to be effective and if psychiatrists are to retain control of their own destiny they must recognise that they will no longer be allowed to cover up for sick, lazy or incompetent colleagues. If psychiatrists allow their activities to be controlled by uninformed lay people who lack insight into the very difficult issues they face their future will be bleak.

Psychiatrists seem reluctant to pay greater attention to their public image. Their College has accepted the urgent need for a stronger public profile by appointing a firm of public relations experts to help deal promptly with press and media enquiries but it still has to be shown that this is having a significant impact. The press are understandably eager to publish any hint of scandal about a psychiatrist but fear should not deter closer links with the media which could lead to an improved public image.

The future for psychiatrists depends not just on external threats about which they can do little but much on selfinflicted wounds about which they could do much. A recent editorial in the Lancet entitled 'Psychiatry-a discipline that has lost its way' suggests "Much progress made by psychiatry in the last generation has taken place because psychiatrists themselves have led the way. It is sad that they now appear as forces of reaction and their places as pioneers have been usurped by planners and politicians. It is time for the profession to emerge from its torpor, cease its self flagellation, to take on the mantle of leadership again".

Psychiatrists are going to survive as a species but their future will be better assured if they pay more attention to the part they themselves play in bringing about the difficulties which concern them. While their destiny does not lie solely in their own hands, there is much they could do to ensure a more satisfactory evolution of their own specialty.

REFERENCES

${ }^{1}$ BIRLeY, J. L. T. (1973) The ghost in the machine. In Policy for Action (eds R. Cawley \& G. McLachlan). Nuffield Provincial Hospitals Trust, Oxford University Press.

${ }^{2}$ Miller, H. (1969) Psychiatry-medicine or magic? World Medicine, December 1969, 44-52.

${ }^{3}$ Rosenhan, D. L. (1973) Psychiatrists engaged in diagnostic behaviour. World Medicine, April 1973, 36-38.

${ }^{4}$ RAWNsLeY, K. (1984). Psychiatry in jeopardy. British Journal of Psychiairy. 145, 573-578. 
${ }^{5}$ KENDELL, R. E. (1987) The future of psychiatric research in Britain. Bethlem \& Maudsley Gazette, 34, 24-25.

${ }^{6} \mathrm{HILL}$, D. (1978) The qualities of a good psychiatrist. British Journal of Psychiatry, 133, 97-105.

'JONEs, K. (1978) Society looks at the psychiatrist. British Journal of Psychiatry, 132, 321-332.

${ }^{8}$ GreBen, S. E. (1987) Psychotherapy today. British Journal of Psychiatry, 151, 283-287.

${ }^{9}$ Kreitman, N. (1962) Psychiatric orientation: A study of attitudes among psychiatrists. Journal of Mental Science, 108, 317-328.
${ }^{10}$ CaIn, T. M. \& SmaIL, D. J. (1979) The Treatment of Mental Illness: Science, Faith and the Human Personality. University of London Press.

"PAllis, D. J. \& StofrelmaYr, B. M. (1973) Social attitudes and treatment orientation among psychiatrists. British Journal of Medical Psychology, 46, 75-81.

${ }^{12}$ Mayou, R. (1987) Burnout. British Medical Journal, 295, 84-85.

${ }^{13}$ Murray, R. M. (1987) Problems plus assets. Bethlem \& Maudsley Gazette, 34, 26.

\section{Dialogues on Contemporary Issues}

The British Psycho-analytical Society will be holding a series of dialogues on contemporary issues between distinguished guests and members of the Society at the
Institute of Psycho-Analysis during the Summer Term 1988 from $6.00-7.45 \mathrm{pm}$ on the following dates:

\begin{aligned} & \multicolumn{1}{c}{ Title of Dialogue } \\ May 4 & Society as a Field of Study \\ 11 & Crime and Punishment \\ 18 & Quis Custodiet-Nuclear Disarmament \\ & and the Military Mind \\ 25 & Psychoanalysis and Social Anthropology \\ June 1 & Leadership \\ 8 & The Character of Mind \\ 15 & Art and Psychoanalysis \\ 22 & Tranquility-An Epicurean State of Bliss \\ 29 & Is Depression an Illness? \end{aligned}

Admission by ticket only; fee for each Dialogue is $£ 5$. Applications for tickets, quoting specific dates and enclosing a cheque made payable to the INSTITUTE OF PSYCHOANALYSIS, together with a stamped and self-addressed

\begin{tabular}{|c|c|}
\hline $\begin{array}{l}\quad \text { Guest } \\
\text { Dr Eric Miller } \\
\text { Dr David A. Thomas } \\
\text { Air Comm. A. Mackie }\end{array}$ & $\begin{array}{l}\quad \text { Member } \\
\text { Mrs Isabel Menzies Lyth } \\
\text { Dr Nicholas Temple } \\
\text { Dr Hanna Segal }\end{array}$ \\
\hline $\begin{array}{l}\text { Dr Audrey Cantlie } \\
\text { Dr John Rae } \\
\text { Mr Colin McGinn } \\
\text { Prof Sir Ernst Gombrich } \\
\text { Prof Myles Burnyeat } \\
\text { Prof Arthur Crisp }\end{array}$ & $\begin{array}{l}\text { Mrs Elizabeth Spillius } \\
\text { Mr Michael Brearley } \\
\text { Dr Dennis Duncan } \\
\text { Prof Joseph Sandler } \\
\text { Dr John Padel } \\
\text { Dr Clifford Yorke }\end{array}$ \\
\hline
\end{tabular}

envelope, should be sent to: The Executive Secretary, Institute of Psycho-Analysis, 63 New Cavendish Street, London WIM 7RD.

\section{The British Neuropsychiatry Association}

The formation of The British Neuropsychiatry Association has been announced with Chairman: Professor W. A. Lishman; Secretary: Dr J. M. Bird; Treasurer: Dr M. Robertson; Committee Members: Dr E. H. Reynolds (neurologist), Dr M. Wyke (neuropsychologist).

The aim of this Association will be to encourage crossdisciplinary discussion of clinical and academic issues of common interest within the fields of neurology, psychiatry and neuropsychology. All interested professionals in those and allied disciplines are warmly invited to join Academic and clinical meetings will be held twice yearly. Subscription rate will be $£ 10$ per annum - to include attendance at and abstracts of those meetings. Cheques, payable to 'The British Neuropsychiatry Association', should be sent to Dr Mary Robertson, Academic Department of Psychiatry, The Middlesex Hospital, London WIN 8AA.

Subscriptions should be sent before 17 June.

The next meeting will be held at the National Hospital, Queen Square, London WCIN 3BG On 8 July 1988. The topic will be 'The Neuropsychiatry of the Frontal Lobes'. Speakers will include: S. Lewis (schizophrenia), C. Binnie (seizures), R. Jacobsen (alcoholism), D. Neary (dementia), J. Bird (personality), A. Lees (Parkinson's disease), E. Taylor (hyperkinesis), R. Passingham (psychology), and T. Robins (neurochemistry).

Further details: Dr J. M. Bird, Burden Neurological Hospital, Stoke Lane, Stapleton, Bristol BS16 1QT. 